\title{
artigo
}

Santana, A.G.C.; Cerqueira, F.P.; Macêdo, W.A.B.; Carneiro, B.R.; Silveira, C.A.O.; Brito, J.S.; Oliveira da Silva, M.; Barbosa, F.R.;

Análise de protocolos no atendimento ao paciente em parada cardiorrespiratória com suspeita ou diagnóstico de COVID-19

\section{Análise de protocolos no atendimento ao paciente em parada cardiorrespiratória com suspeita ou diagnóstico de COVID-19}

Analysis of protocols in the care of patients in cardiorespiratory arrest with suspicion or diagnosis of COVID-19

Análisis de protocolos enlaatención de pacientes en parada cardiorrespiratoriaconsospecha o diagnóstico de COVID-19

\begin{abstract}
RESUMO
Objetivo: Analisar os protocolos de atendimento ao paciente em parada cardiorrespiratória com suspeita ou diagnóstico de covid-19. Método: Realizou-se de uma revisão integrativa qualitativa, exploratória e de abordagem documental, utilizando as bases de dados PubMed, SciELO, diretrizes da American Heart Association (AHA), Sociedade Europeia de Cardiologia (ESC) e protocolos institucionais do Ebersh. Foram selecionados 03 protocolos e 07 artigos que abordaram de forma direta a temática. Resultados: Os objetivos dos protocolos são similares, embora alguns não deixem instituídos de forma sistematizada a atribuição de cada profissional no manejo da Parada Cardiorrespiratória (PCR). Todos os artigos enfatizaram a necessidade da paramentação completa e correta antes prestar assistência ao paciente com suspeita ou confirmado para covid-19. Conclusão: Os protocolos corroboram nos seguintes quesitos: utilização da paramentação adequada; o quantitativo de profissionais envolvidos na cena da PCR; às drogas utilizadas e a utilização da técnica de intubação e respiração que gere menos aerossóis.

DESCRITORES: Doenças Cardiovasculares; Infecções por Coronavírus; Parada Cardíaca; Cuidados Críticos.
\end{abstract}

\section{ABSTRACT}

To analyze the protocols for patient care in cardiorespiratory arrest with suspicion or diagnosis of covid-19. Method: A qualitative, exploratory and documentary integrative review was carried out, using the PubMed, SciELO, American Heart Association (AHA), European Society of Cardiology (ESC) and Ebersh institutional protocols databases. Three protocols and seven articles were selected that directly addressed the theme. Results: The objectives of the protocols are similar, although some do not allow the attribution of each professional in the management of Cardiopulmonary Arrest (CRP) to be systematically established. All articles emphasized the need for complete and correct attire before providing assistance to a suspected or confirmed patient for covid-19. Conclusion: The protocols corroborate the following requirements: use of adequate vestment; the number of professionals involved in the PCR scene; the drugs used and the use of the intubation and breathing technique that generates less aerosols.

DESCRIPTORS: Cardiovascular diseases; Coronavirus infections; Cardiac Arrest; Critical Care.

\section{RESUMEN}

Objetivo: Analizar los protocolos de atención al paciente en parada cardiorrespiratoria con sospecha o diagnóstico de covid-19. Método: Se realizó una revisión integrativa cualitativa, exploratoria y documental, utilizando las bases de datos de protocolos institucionales PubMed, SciELO, American Heart Association (AHA), European Society of Cardiology (ESC) y Ebersh. Se seleccionaron tres protocolos y siete artículos que abordaron directamente el tema. Resultados: Los objetivos de los protocolos son similares, aunque algunos no establecen de forma sistemática la atribución de cada profesional en el manejo de la Parada Cardiorrespiratoria (PCR). Todos los artículos enfatizaron la necesidad de una vestimenta completa y correcta antes de brindar asistencia a un paciente sospechoso o confirmado de covid-19. Conclusión: Los protocolos corroboran los siguientes requisitos: uso de vestimenta adecuada; el número de profesionales involucrados en la escena de PCR; los fármacos utilizados y el uso de la técnica de intubación y respiración que genera menos aerosoles.

DESCRIPTORES: Enfermedades Cardiovasculares; Infecciones por Coronavirus; Paro Cardiaco; Cuidado Crítico.

RECEBIDO EM: 30/01/2021 APROVADO EM: 16/02/2021 


\section{Árgila Gonçalves de Carvalho Santana}

Enfermeira. Especialista em Gestão Hospitalar. Residente de Enfermagem em Cardiologia pela Universidade Federal do Recôncavo da Bahia; Atua como enfermeira residente no Hospital Ana Nery, Integrante dos grupos de pesquisa CRIAl, GpCardio e Nipes, Salvador, BA, Brasil.

ORCID: 0000-0001-9590-2127

\section{Fabiane Pereira Cerqueira}

Enfermeira. Pós Graduanda em Enfermagem em Cardiologia pela Escola bahiana de medicina e saúde pública; Atua como Enfermeira Assistencial na Unidade de Terapia Intensiva do Instituto Couto Maia e na UPA San Martin. Preceptora pela Unime. Salvador,BA,Brasil.

ORCID: 0000-0003-3847-2145.

\section{Wadson Andrey Batista Macêdo}

Enfermeiro.Pós Graduando em Enfermagem em Cardiologia pela Escola bahiana de medicina e saúde pública. Coordenador da Clínica Cardiológica, Médica, Cirurgica e Ala Covid do Hospital Promatre e Enfermeiro Assistencial da UTI Covid da Policlínica Grupo DeVry/Brasil; Juazeiro, BA, Brasil.

ORCID: 0000-0002-6961-1438

\section{Bruna Rafaela Carneiro}

Enfermeira. Especialista em Urgência e Emergência. Especialisna em Nefrologia. Universidade Estadual de Feira de Santana; Atua como enfermeira assistencial no Hospital Santa Casa de Misericórdia de Feira de Santana. Feira de Santana, Bahia, Brasil. ORCID: 0000-0002-6205-4683

\section{Carolina Amorim de Oliveira Silveira}

Enfermeira. Especialista em Nefrologia e Auditoria. Universidade Católica do Salvador; Coordenadora do setor de Urologia, Nefrologia e Transplante Renal do Hospital Santa Casa de Misericórdia de Feira de Santana. Feira de Santana, Bahia, Brasil.

ORCID: 0000-0002-5177-5485

\section{Jhônata Santos Brito}

Graduando em Enfermagem. Faculdade de Ciências e Empreendedorismo - FACEMP, Integrante do grupo de pesquisa Liati. Santo Antônio de Jesus, BA, Brasil.

ORCID: 0000-0002-8161-5677

\section{Magda Oliveira da Silva}

Enfermeira- Centro Universitário de Juazeiro do Norte; Atua no Hospital Promatre, Juazeiro-BA.

ORCID: 0000-0002-4846-0925

\section{Felix da Rocha Barbosa}

Graduando em Enfermagem. Universidade Salvador. Salvador, Bahia, Brasil. ORCID: 0000-0003-0256-5147

\section{INTRODUÇÃO}

A Parada Cardiorrespiratória (PCR) é definida como a cessação abrupta das funções cardíacas, respiratórias e cerebrais, sendo comprovada pela tríade: ausência de pulso central (carotídeo/ femoral), de movimentos ventilatórios (apneia), ou respiração agônica, além do estado de inconsciência. ${ }^{1}$

A principal causa da PCR extra-hospitalar em adultos é a síndrome coronariana aguda; sendo essa considerada uma emergência devido a sua gravidade e elevada morbimortalidade. ${ }^{2}$ Nesse contexto dois fatores importantes são considerados para retorno da circulação espontânea: a reanimação cardiopulmonar (RCP) e desfibrilação em ritmos chocáveis. ${ }^{2 ; 3}$

A PCRé algo que está susceptível a acontecer em pacientes graves acometidos pela doença por coronavírus 2019 (covid-19) que é causada pelo vírus SARS-CoV-2, um vírus recém-emergente, altamente patogênico, com transmissibilidade por vias respiratória e contato, que até janeiro de 2021 foi responsável por 198.974 óbitos no Brasil e 1.884 .266 mortes no mundo. ${ }^{4}$
As pessoas acometidas podem evoluir para as formas graves da doença, de repercussão sistêmica, com rápida e súbita piora clínica, podendo levar a PCR, tanto para ritmos chocáveis quanto para os não chocáveis. ${ }^{5,6}$ É fundamental a insersão de protocolos institucionais e políticas no ambiente hospitalar e pré-hospitalar para orientar na determinação da adequação do início e do término da RCP para pacientes com Covid-19, uma vez que quanto mais fatores de risco o paciente tenha, maior a probabilidadedede um desfecho desfavoráveis. Estratificação e políticas de 


\section{artigo}

Santana, A.G.C.; Cerqueira, F.P.; Macêdo, W.A.B.; Carneiro, B.R.; Silveira, C.A.O.; Brito, J.S.; Oliveira da Silva, M.; Barbosa, F.R.;

Análise de protocolos no atendimento ao paciente em parada cardiorrespiratória com suspeita ou diagnóstico de COVID-19

risco devem ser comunicadas aos pacientes durante os objetivos das discussões sobre cuidados. ${ }^{20}$

Diante do cenário de incertezas quanto ao impacto da pandemia na saúde das pessoas, faz-se necessário a utilização de protocolos bem definidos. ${ }^{15} \mathrm{O}$ risco de contágio da equipe aumenta em decorrência da limitação de recursos em alguns estados brasileiro, principalmente nas regiões que enfrentam grande número de casos da doença. Embora os resultados da parada cardiorrespiratória relacionado a Covid-19 ainda sejam desconhecidos, a mortalidade de pacientes com a doença em estado crítico é elvada e quanto mais comorbidades associadas relacionada as doenças cardiovasculares a chance de evolução para uma PCR aumenta. ${ }^{9}$

À medida que observarmos uma melhor integração da equipe com os protocolos; uma melhor definição de papéis o que facilita na otimização da assistência, favorecendo a tomada de decisões de forma segura, rápida e coesa, uma vez que a covid-19 é uma doença altamente contagiosa e a PCR é um evento agudo letal. Nesta perspectiva confrontar e analisar os protocolos disponíveis sobre o manejo da PCR em pacientes com suspeita ou confirmação de covid é fundamental para orientar a equipe assistente nas condutas de segurança a serem tomadas, para evitar/ minimizar a aerossolização e dos profissionais durante o procedimento.

Diante do exposto, este estudo objetiva analisar os protocolos de atendimento ao paciente em parada cardiorrespiratória com suspeita ou diagnóstico de covid 19.

\section{MÉTODO}

Trata-se de uma revisão integrativa qualitativa, exploratória, com uma abordagem documental, realizada no período de novembro de 2020 a janeiro de 2021. A presente revisão cumpriu todas as etapas de construção da questão norteadora: $\mathrm{O}$ que traz como recomendações os protocolos de atendimento ao paciente em parada cardiorrespiratória com suspeita ou diagnóstico de covid 19 ?

Os dados foram coletados utilizando o recorte temporal dos protocolos e artigos publicados de março de 2020 a janeiro de 2021. As buscas foram realizadas nas bases de dados Biblioteca Virtual em Saúde (BVS), Pubmed, SciELO, Protocolos institucionais da Ebersh e diretrizes da American Heart Association (AHA), ABRAMEDE, AMIB, AMB e Sociedade Brasileira e Europeia de Cardiologia. Foi utilizado os seguintes descritores através das palavras chave: Doenças Cardiovasculares; Infecções por Coronavírus; Parada Cardíaca; Cuidados Críticos; acompanhados dos operadores boleanos "AND" e "OR".

Os critérios de inclusão foram para artigos científicos, Guidelines e Protocolos Institucionais na íntegra publicados de 2020 a 2021, nacionais e internacionais, que avaliassem variáveis clínicas e manejo da parada cardiorrespiratória em pacientes

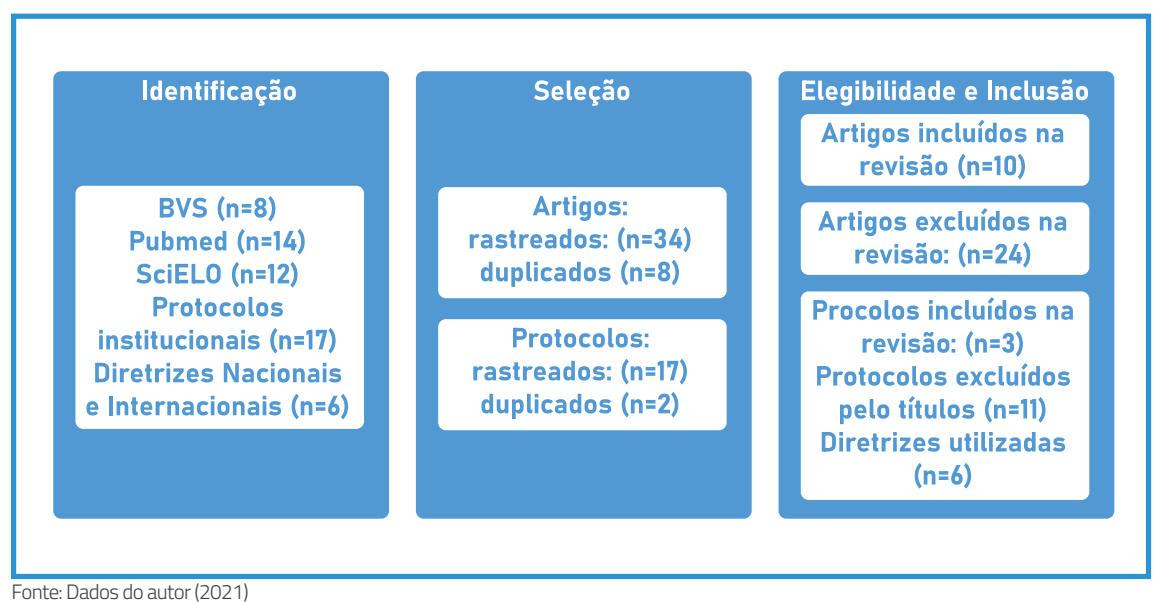

Fonte: Dados do autor (2021) com suspeita ou confirmação de covid-19. Já o de exclusão foram para os artigos e protocolos de literatura cinzenta ou cuja que não atendiam a temática de forma específica ou não disponíveis na íntegra e os protocolos de parada que não fossem específicos para paciente com covid-19.

Após a seleção dos artigos foi utilizado para a organização dos dados a estratégia Preferred Reporting Items for Systematic Review and Meta-Analyses (PRISMA) para promover o relato da presente revisão $^{18}$. A recomendação PRISMA consiste em seguir quatro etapas: identificação dos artigo; seleção; elegibilidade e inclusão com intuito de ajudar os autores a melhorar a apresentação dos dados da revisão19. O fluxograma apresentado na Figura 1 descreve a utilização desse método de forma adaptada para este estudo.

Os dados extraídos dos protocoos foram analisados, interpretados e apresentados de forma descritiva em quadro síntese. Posteriormente foi realizado a discussão do que traz os artigos e diretrizes da American Heart Association (AHA), ABRAMEDE, AMIB, AMB e Sociedade Brasileira e Europeia de Cardiologia em comparação com os protocolos institucionais selecionados.

Conforme a resolução 466/2012 não foi necessária apreciação do comitê de ética em pesquisa por se tratar de uma revisão sistemática. A pré-seleção dos artigos através da analise da temática e do título dos trabalhos, posteriormente foi realizado a leitura na íntegra dos resumos recuperados. Após isso, os artigos selecionados passaram por leitura crítica, com objetivo de explanar a dinâmica da parada cardiorrespiratória em pacientes com suspeita ou diagnóstico de covid-19.

\section{RESULTADOS}

A busca resultou na visualização de um total de 34 publicações em forma de artigo; 17 protocolos e 6 diretrizes. Dentre esses, 11 estudos estavam elegíveis para a análise de acordo com os critérios previamente estabelecidos. Assim, para análise foram selecionados os protocolos institu- 
Figura 1 - Fluxograma baseado em protocolos institucionais da dinâmica de atendimento ao paciente com suspeita ou diagnóstico de covid-19. Salvador, BA, Brasil, 2021.

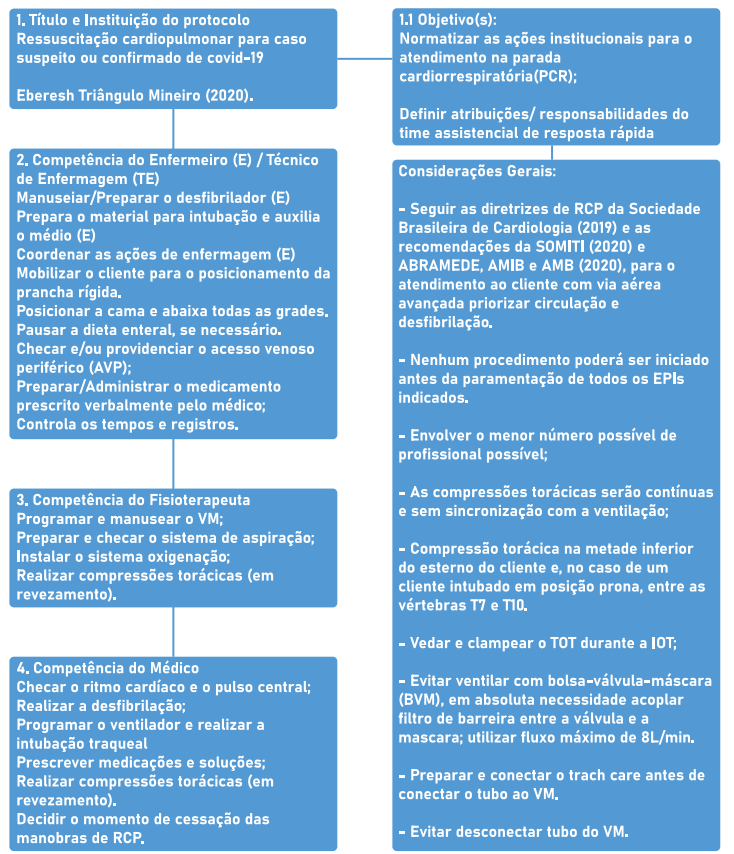

Fonte: Dados do autor (2021)

Figura 2 - Fluxograma baseado em protocolos institucionais da dinâmica de atendimento ao paciente com suspeita ou diagnóstico de covid-19. Salvador, BA, Brasil, 2021.

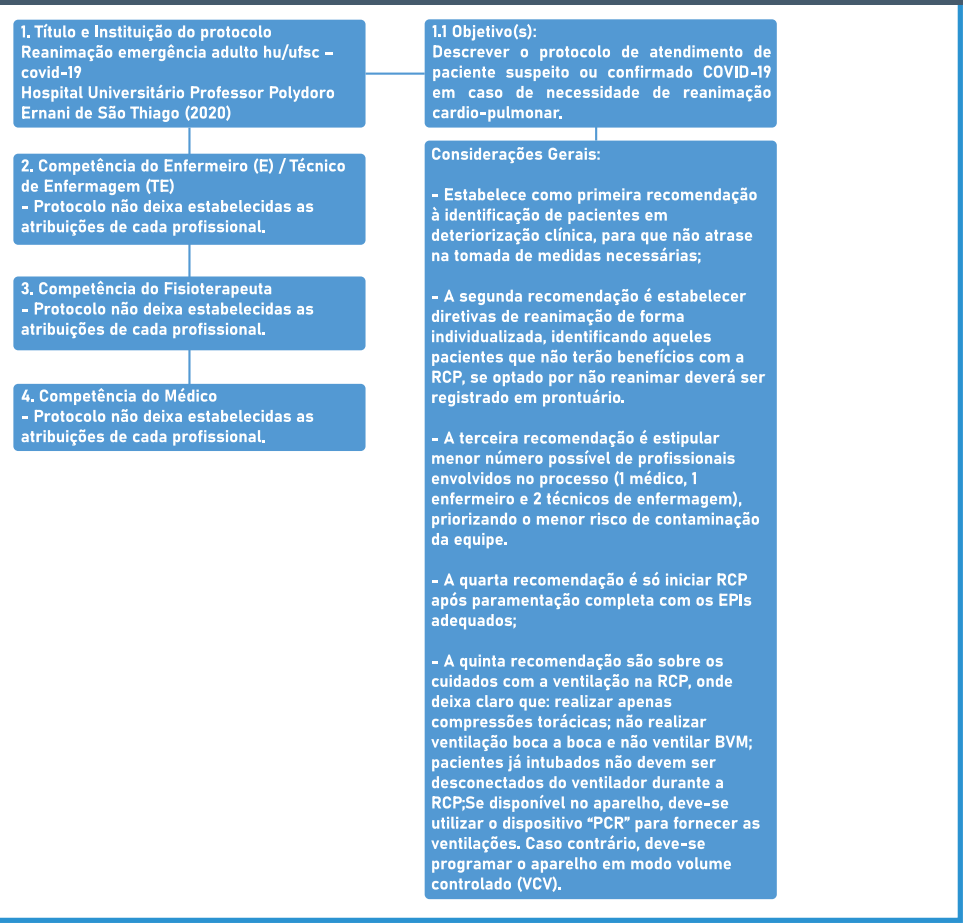

Fonte: Dados do autor (2021) cionais distribuídos conforme as instituições e recorte temporal de publicação.

No que se refere à dinâmica na $\mathrm{PCR}$ do paciente com suspeita ou diagnóstico da covid-19, os protocolos selecionados apresentam algumas considerações que concordam entre si como é apresentado no Fluxograma, representado pela Figura 1 a 3 .

Os autores corroboram no que tange os objetivos, embora um dos protocolos não tenha deixado instituído de forma separada a atribuição de cada profissional no manejo da PCR todos tiveram uma significância colaborativa. Dessa maneira, com a finalidade de atender ao objetivo do estudo, realizou-se a discussão dos resultados, conforme discorre o tópico seguinte.

\section{DISCUSSÃO}

Alguns estudos desenvolvidos no desenvolver da pandemia pela Sars-CoV2 demonstraram alguns efeitos específicos do Covid-19 no sistema cardiovascular. ${ }^{8,9}$ Há evidências de arritmias, taquicardia, infarto agudo do miocárdio, dentre outras que podem aparecer de forma concomitante em pacientes infectados, os casos mais graves e que evoluem para eventos de parada cardiorrespiratória estão associados àqueles indivíduos com mais comorbidades e fatores de risco que necessitam cuidados mais intensivos. ${ }^{6,7}$

A alta incidência de Covid-19 associados a sintomas cardiovasculares é decorrente a resposta inflamatória sistêmica e distúrbios do sistema imunológico durante a progressão da doença, podendo assim ter pior prognóstico. ${ }^{8}$ Em condições clínicas onde os pacientes com suspeita ou covid-19 evoluam para parada cardiorrespiratória é necessário seguir os protocolos institucionais estabelecidos para a situação. Os resultados da utilização dos protocolos evidenciam resultados positivos e efetivos com sua utilização, pois se trata de uma ferramenta moderna e que influencia diretamente na assistência. ${ }^{14}$

Poucos foram os protocolos disponíveis na íntegra que abordassem a temática, dos três disponíveis, dois deles trouxeram 


\section{artigo}

Santana, A.G.C.; Cerqueira, F.P.; Macêdo, W.A.B.; Carneiro, B.R.; Silveira, C.A.O.; Brito, J.S.; Oliveira da Silva, M.; Barbosa, F.R.;

Análise de protocolos no atendimento ao paciente em parada cardiorrespiratória com suspeita ou diagnóstico de COVID-19

Figura 3 - Fluxograma baseado em protocolos institucionais da dinâmica de atendimento ao paciente com suspeita ou diagnóstico de covid-19. Salvador, BA, Brasil, 2021.
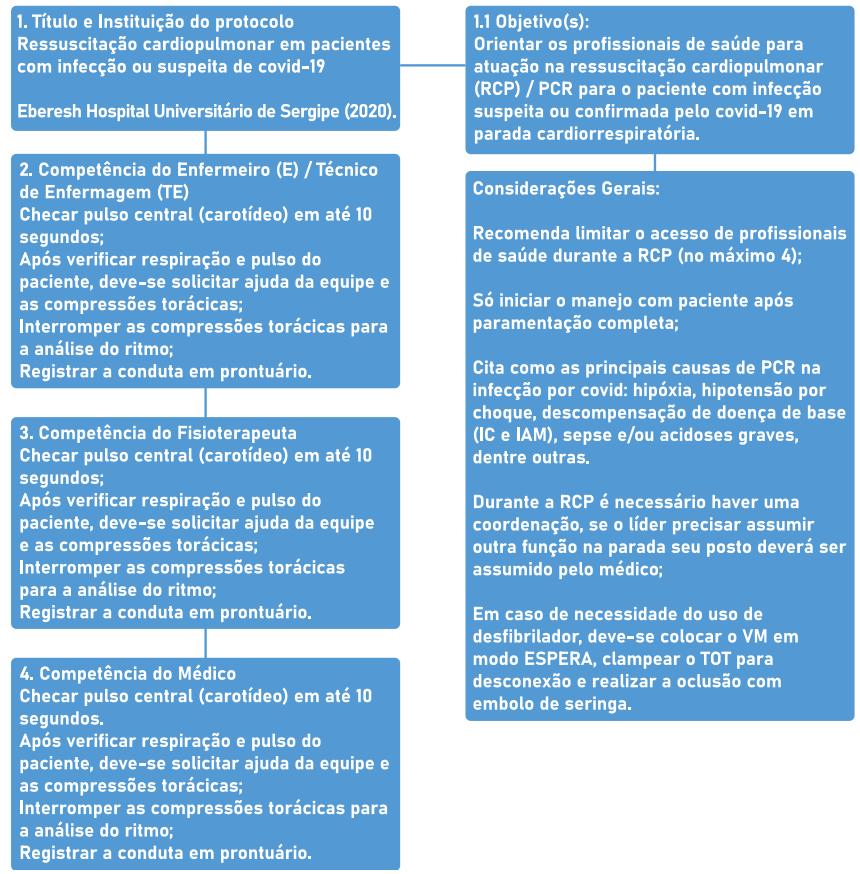

Fonte: Dados do autor (2021)

bem definidos o papel de cada membro da equipe multidisciplinar (enfermeiro, fisioterapeuta e médico). Os três protocolos corroboraram no que tange que a equipe deve ser composta por no máximo 4 pessoas $^{11,12,13}$; que as manobras de RCP só devem ser iniciadas após paramentação adequada. No que tange o uso dos equipamentos de proteção individual (EPI) os autores corroboram com essa necessidade que traz os protocolos, pois evita a contaminação entre profissionais e a contaminação cruzada ${ }^{15}$.

O protocolo ${ }^{11,12,13}$ ressaltam a importância da detecção rápida de sinais de deteriorização ou agravamento do quando. O Hospital Universitário do Triângulo Mineiro em especial traz como protocolo a utilização do Escore Modificado de Alerta Precoce que é uma ferramenta que vem sendo utilizada para o reconhecimento precoce da deterioração dos pacientes, é calculado a soma das pontuações atingidas na avaliação dos seguintes parâmetros sensórios: pressão arterial sistólica, tempe-

\section{É necessário}

ressaltar que todos

os protocolos

trazem que o melhor

tratamento continua

sendo a prevenção, e

medidas simples, tais

como lavar as mãos

com sabão, utilizar

álcool em gel e

desinfetar superfícies

como celulares... ratura, frequência respiratória, frequência cardíaca, saturação periférica de oxigênio e da suplementação de O2. ${ }^{17}$

Os protocolos ${ }^{11,13}$ corroboram no que tange a necessidade de prioridade da desfibrilação imediata caso o paciente com suspeita ou diagnóstico de covid-19 esteja em ritmo chocável, não necessitando esperar obter via área e também não priorizar demais procedimentos. A American Heart Association (2015) preconiza essa conduta, ressaltando que a desfibrilação deve ocorrer o mais rápido possível, sendo prioridade sobre outras intervenções ${ }^{16}$.

Proceder com massagem cardíaca conforme American Heart Association (2015) é preconizado 100 a 120 compressões por minuto corroborando com os protocolos analisados.Se ritmo chocável, realizar choque imediatamente (200J bifásico e 360 monofásico). ${ }^{11,13}$ As drogas de escolha só são abordadas no protocolo $11 \mathrm{e}$ traz com droga de escolha a Adrenalina $1 \mathrm{mg}$ para todos os ritmos de parada; a partir do terceiro ciclo de RCP considerar Amiodarona $300 \mathrm{mg}$ como dose de ataque e dose de $150 \mathrm{mg}$ como dose de manutenção, sempre considerar as causas reversíveis; os demais protocolos não citam as drogas de escolhas no momento da parada.

$\mathrm{O}$ protocolo $^{11}$ ressalta a importância de identificar aqueles pacientes que não terão benefícios com a RCP e se optado por não reanimar deverá ser registrado em prontuário pela equipe multidisciplinar. É necessário ressaltar que todos os protocolos trazem que o melhor tratamento continua sendo a prevenção, e medidas simples, tais como lavar as mãos com sabão, utilizar álcool em gel e desinfetar superfícies como celulares, desempenham um papel essencial na redução da propagação do vírus.

\section{CONCLUSÃO}

O manejo com paciente infectados pela covid-19 ainda é pátio para várias discussões e implementação de melhorias dos protocolos, uma vez que essa doença vem sofrendo mutações e técnicas que minimizem o contágio estão sempre em análise e estudo.Uma das grandes entraves para rea- 
lização do estudo foi a pouca disponibilidade de protocolos disponíveis na internet para análise e nota-se que os protocolos disponíveis são em geral dos hospitais escolas da Ebserh.

Um dos protocolos analisados não determina as funções de cada profissional (médico, enfermeiro e fisioterapeuta) durante a PCR em pacientes com suspeita ou diagnóstico de covid-19, o que se faz necessário em todos os protocolos institucionais. Ressalta-se que um dos protocolos traz um diferencial que é a utilização do escore de alerta precoce e as orientações no manejo pós-parada.

Fica como sugestão a implementação desses tópicos (o escore e orientações pós-parada) nos demais protocolos insti- tucionais, pois o escore auxilia na tomada de decisões de forma precoce e avaliação pós-parada previne nos eventos, incluindo uma nova PCR. Também nota-se que ambos corroboram na importância do profissional está devidamente paramentado antes de prestar qualquer assistência ao paciente com suspeita ou diagnóstico de covid.

\section{REFERÊNCIAS}

1. Bernoche C, Timerman S, Polastri TF, Giannetti NS, Siqueira AWS, Piscopo A et all. Atualização da Diretriz de Ressuscitação Cardiopulmonar e Cuidados de Emergência da Sociedade Brasileira de Cardiologia - 2019. ArqBrasCardiol. 2019; 113(3):449663.doi: http://dx.doi.org/10.5935/abc.20190203

2. Xavier AR., Silva JS., Almeida JPCL., Conceição JFF., Lacerda GS., Kanaan S. COVID-19: manifestações clínicas e laboratoriais na infecção pelo novo coronavírus. J. Bras. Patol. Med. Lab. 2020; 56.doi: http://dx.doi.org/10.5935/1676-2444.20200049

3. Nascimento JCP, Rocha RRA, Dantas JKS, Oliveira ES, Dantas DV, Dantas RAN. Manejo de pacientes diagnosticados ou com suspeita de covid-19 em parada cardiorrespiratória: scopingreview. Texto contexto - enferm. 2020; 29; 1-17.doi: http://dx.doi. org/10.1590/1980-265x-tce-2020-0262.

4. Ministério da Saúde, Secretaria de Vigilância em Saúde. BOLETIM EPIDEMIOLÓGICO. Doença pelo CoronavírusCOVID-19. 2021Jan

5. Pereira RSM, Pinheiro MBGN, Bezerra AMF, Bezerra KKS, Bezerra WKT, Abreu RA et all. Parada cardiorrespiratória e reanimação cardiopulmonar: conhecimento de enfermeiros de um hospital público no Alto Sertão Paraibano. Rev INTESA. 2015;9(2); 01-10. ISSN 2317-305X.

6. Di Pasquale G. Coronavirus COVID-19: Qualiimplicazioni per laCardiologia? G ItalCardiol. 2020;21(4):243-5.doi: http://dx.doi. org/10.1714/3328.32981

7. Nunes, L.T.D.; Felipe, L.E.C.; Gonçalves, I.M.; Alves, O.N.;Principais Manifestações Neurológicas decorrentes do COVID-19: uma revisão integrativa. Revista Saúde Coletiva. 2020; 10(59); 4242-4254. doi: https://doi.org/10.36489/saudecoletiva.2020v10i59p4248-4254.

8. Strabelli TMV, Uip DE. COVID-19 e o coração. ArqBrasCardiol. 2020;144(4); 598-600.doi: http://dx.doi.org/10.36660/ abc.20200209

9. Ruan Q, Yang K, Wang W, Jiang L, Song J. Clinical predictors of mortality due to COVID-19 based on an analysis of data of 150 patients from Wuhan, China. Intensive Care Med. 2020;46(5); 846-8.doi: 10.1007 / s00134-020-05991-x.

10. Ferrari Filipe. COVID-19: Dados Atualizados e sua Relação Com o Sistema Cardiovascular. Arq. Bras. Cardiol. 2020; 114 (5): 823-826. doi: http://dx.doi.org/10.36660/abc.20200215.

11. Hospital de Clínicas do Triângulo Mineiro. Hospitais Universi- tários Federais EBSERH. Protocolo de Ressuscitação cardiopulmonar para caso suspeito ou confirmado de covid-19. 2020;118; Versão 1.

12. Hospital Universitário Professor Polydoro Ernani de São Thiago. Hospitais Universitários Federais EBSERH.Protocolo de Reanimação emergência adulto HU/UFSC- covid-19. 2020;1-4; Versão 001.

13. Hospital Universitário de Sergipe. Hospitais Universitários Federais EBSERH. Protocolo de Reanimação cardiopulmonar em pacientes com infecção suspeita ou confirmada pelo covid-19. 2020;1-14; Versão 1.

14. Sales CB, Bernardes A, Silvia GC, Brito MFP, Moura AA, Zanetti $A C B$. Protocolos Operacionais Padrão na prática profissional da enfermagem: utilização, fragilidades e potencialidades. Rev. Bras. Enferm. 2018; 71(1); 126-134. doi: https://doi. org/10.1590/0034-7167-2016-0621.

15. Arnold RH, Tideman PA, Devlin GP, Carroll GE, Elder A, Lowe $\mathrm{H}$, et al. Rural and Remote Cardiology During the COVID-19 Pandemic: Cardiac Society of Australia and New Zealand (CSANZ) Consensus Statement. Hear Lung Circ. 2020;1-6. doi: https://doi. org/10.1016/j.hlc.2020.05.001.

16. American Heart Association. Destaques da American Heart Association 2015: atualização das diretrizes de RCP e ACE. AHA. 2015.

17. Montenegro SMSL, Miranda CH. Avaliação do desempenho do escore de alerta precoce modificado em hospital público brasileiro. Rev. Bras. Enferm. 2019; 72(6): 1428-1434. doi: https:// doi.org/10.1590/0034-7167-2017-0537.

18. Galvão TF, Pansani TSA, Harrad D. Principais itens para relatar Revisões sistemáticas e Meta-análises: A recomendação PRISMA. Epidemiol e Serviços Saúde. 2015; 24(2):335-342. doi: 10.5123/S1679-49742015000200017

19. Pike A, Brandon, S. Evaluation of ASTM Standard Test Method E 2177, 6 Retroreflectivity of Pavement Markings in a Condition of 7 Wetness. Syst Rev. 2012;1:1-9. doi: https:// org/10.3141/2272-10.

20. D'cruz M, Banerjee D. 'An invisible human rights crisis': The marginalization of older adults during the COVID-19 pandemic - An advocacy review. Psychiatry Res. 2020;292:113369. doi:https://org/10.1016/j.psychres.2020.113369. 